\title{
Tobacco control: an investment that leads to global development
}

\author{
Michał Stokłosa \\ American Cancer Society, Atlanta, GA, USA
}

\begin{abstract}
Because health improvements and economic growth are strongly interrelated, it is imperative to consider health as a critical matter in the world's economic prosperity. For example, it is estimated that between 2000 and 2011, about $24 \%$ of full income growth in low-income and middle-income countries worldwide resulted from health improvements. This year's World No Tobacco Day focused on the crucial role that tobacco control plays in achieving sustainable development. The World Health Organization highlighted that tobacco control policies are stimuli for economic growth and called on countries to prioritize and accelerate tobacco control in their efforts to reach their development goals.
\end{abstract}

ADDRESS FOR CORRESPONDENCE: Michał Stokłosa, American Cancer Society, 250 Williams Street, 30303 Atlanta, United States, e-mail: michal.stoklosa@cancer.org

When a nation goes from poverty to prosperity, it makes the world stronger and a better place for everybody, because history demonstrates that shared prosperity tends to beget both peace and more prosperity. With the aim of maintaining and accelerating the world's progress in achieving sustainable development, on September $25^{\text {th }}$, 2015 the 194 countries of the United Nations (UN) General Assembly adopted the 2030 Agenda for Sustainable Development. The Agenda outlines 17 Sustainable Development Goals and the associated 169 targets necessary for creating a thriving global society. These goals and targets were carefully selected based on the vast, existing body of research evidence. Achieving these targets is a prerequisite for overcoming the threats that could undermine the prosperity of all people and for improving the welfare of current and future generations [1].

One of the key goals adopted by the UN is to ensure healthy lives and promote well-being for all people of all ages. Making health one of the pillars of sustainable development seems natural, since most people see their health as an important component of their well-being. Few people, however, fully realize the extent to which achieving greatly improved world development is dependent upon meeting the health-related targets. First, both health and the economy are equally important in serving society. As noted by Angus Deaton, the 2015 Nobel laureate in Economic Sciences: "Health is the obvious starting point for an enquiry into wellbeing. You need a life to have a good life" [2]. Put simply, the world's development cannot be measured by economic indicators alone, without any regard to health, because people cannot enjoy the benefits of economic prosperity if they are dead. Many organizations have already realized the importance of health indicators in measuring the world's progress. For example, the UN regularly publishes the Human Development Index, a score intended to rank countries' development based not only on their gross domestic product (GDP), but also on the length and quality of health of the lives of citizens of those countries [3].

Further, because health improvements and economic growth are strongly interrelated, we cannot view health solely as a matter of individual well-being, but must also consider it as a critical matter in the world's economic prosperity. A seminal study published in the leading health journal "The Lancet" found that there is an enormous payoff from investing in health. The study estimated that, between 2000 and 2011, about 24\% of full income growth in low-income and middle-income countries worldwide resulted from health improvements [4]. In Sub-Saharan Africa, the share of growth resulting from health improvements during that period was even higher, at 69\% [4]. The relationship also works the other way around: countries with higher per capita GDP tend to yield better health results for their citizens [5]. Thus, health improvements 
and economic growth are mutually reinforcing factors for world development.

This year's World No Tobacco Day focuses on the crucial role that tobacco control plays in achieving sustainable development. It should go without saying that tobacco control is one of the most important, effective, and efficient measures in public health [6] In fact, achieving some of the key Sustainable Development targets related to public health, such as ending the tuberculosis epidemic or reducing premature mortality from non-communicable diseases by one third, will not be possible without strong tobacco control measures. Furthermore, since tobacco use is a drain on economies, measures to control tobacco use boost economic growth. Recent research estimates that the total economic cost of smoking globally amounts to 2 trillion dollars, when adjusted for 2016 purchasing power parity (PPP), an amount equivalent in magnitude to almost $2 \%$ of the world's total economic output [7]. Most of the total economic cost of smoking is the indirect cost, which captures the productivity lost due to morbidity and premature mortality attributable to smoking. With strong tobacco control measures in place, people live longer and more productive lives and a large part of the tobacco-related economic costs is avoided.

Tobacco use generates not only direct costs related to treating tobacco-attributable diseases and indirect costs of lost productivity, but also costs related to forgone opportunities. A monograph on the economics of tobacco and tobacco control recently published by the US National Cancer Institute and the World Health Organization notes that many families living on the verge of poverty have suf-

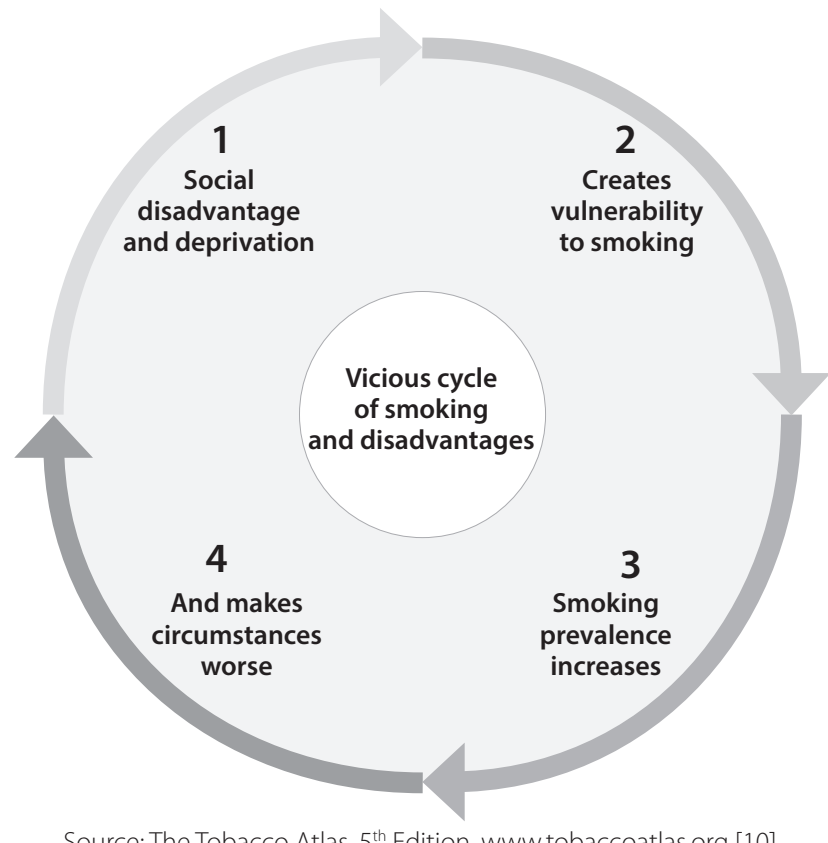

FIG. 1. Vicious cycle of tobacco consumption and poverty. Disadvantage increases smoking likelihood, and smoking increases likelihood of disadvantaged circumstances ficient income and resources to obtain life necessities, but are still impoverished because they forgo a sizable portion of their income to satisfy the debilitating addiction of tobacco use. The tobacco industry purposefully designs cigarettes to addict mostly young people, causing for many a level of economic hardship that they would undoubtedly not choose for their families or themselves [8]. For example, in India, expenditures on tobacco displaced household resources from basic necessities, such as education, milk, and clean cooking fuels, depriving mostly children and women of basic goods and services [9].

In many ways, tobacco and poverty are part of the same vicious cycle. This cycle starts with social disadvantage - such as unemployment, isolation, and stress which often leads to tobacco smoking. Households start allocating their budgets toward tobacco products instead of toward food and other necessities such as health care, education, clothing and financial security. This situation is exacerbated when the households must spend money on treating illnesses caused by tobacco use. Further productivity and income losses from tobacco-related illnesses and deaths contribute to even more poverty. These circumstances lead to more social disadvantages and deprivation, and the cycle continues (Fig. 1).

Effective tobacco control strategies reduce smoking prevalence and, as a consequence, reduce tobacco-related harms, including harms to the economy. On this year's World No Tobacco Day, the World Health Organization highlighted that tobacco control policies - especially tobacco tax increases - are stimuli for economic growth and development, and called on countries to prioritize and accelerate tobacco control in their efforts to reach their development goals. The message is loud and strong: tobacco control is a fundamental investment in human capital, an investment that directly leads to development.

World No Tobacco Day is celebrated every year on May $31^{\text {st }}$. Its purpose is to raise awareness of the risks associated with tobacco use. It has been initiated by the World Health Organisation (WHO) in 1987. One of its main aims is to convince governments to implement measures to tackle tobacco smoking and reduce its health effects. Various events, festivals and anti-tobacco campaigns are held on this occasion, as various public and private organizations are trying to attract people's attention to the issue of the health, social and economic effects of tobacco smoking. Each year the WHO chooses a different message to guide the celebrations. The main topic for World No Tobacco Day on 31 May 2017 was "Tobacco - a threat to development".

\section{DISCLOSURE}

Author reports no conflict of interest.

\section{References}

1. United Nations. Sustainable Development Knowledge Platform. 2017. Available from: https://sustainabledevelopment.un.org/ (accessed: 13 March 2017). 
2. Deaton A. The great escape: health, wealth, and the origins of inequality. Princeton University Press, Princeton 2013.

3. United Nations Development Programme. Human Development Reports. 2017. Available from: http://hdr.undp.org/en/content/human-development-index-hdi (accessed: 13 March 2017).

4. Jamison DT, Summers LH, Alleyne G, et al. Global health 2035: a world converging within a generation. Lancet 2013; 382: 18981955

5. Rosling H. How Does Income Relate to Life Expectancy? Stiftelsen Gapminder, Stockholm 2017. Available from: http://www. gapminder.org/answers/how-does-income-relate-to-life-expectancy/(accessed: 13 March 2017).

6. Laxminarayan R, Chow J, Shahid-Salles SA. Intervention cost-effectiveness: overview of main messages. In: Disease control priorities in developing countries. Oxford University Press, New York 2006; 35-86.

7. Goodchild M, Nargis N, d'Espaignet ET. Global economic cost of smoking-attributable diseases. Tob Control 2017; doi:10.1136/ tobaccocontrol-2016-053305.

8. U.S. National Cancer Institute and World Health Organization. The Economics of Tobacco and Tobacco Control. National Cancer Institute Tobacco Control Monograph 21. NIH Publication No. 16-CA-8029A. U.S. Department of Health and Human Services, National Institutes of Health, National Cancer Institute and World Health Organization, Bethesda 2016.

9. John RM. Crowding out effect of tobacco expenditure and its implications on household resource allocation in India. Soc Sci Med 2008; 66: 1356-1367.

10. Eriksen M, Mackay J, Schluger N, et al. The Tobacco Atlas. $5^{\text {th }}$ ed. American Cancer Society, Atlanta 2015 